\title{
Chapter 16 \\ Sago Starch: Transformation of Extraction and Consumption Processes in Traditional Indonesian Societies
}

\author{
Yoshihiko Nishimura
}

\begin{abstract}
New Guinea Island (NGI) is the origin of sago palm. Sago became a food plant not only in NGI but was also dispersed to Asian areas for use as a staple food. In the current study, the transformation of extraction technology and the trends in sago consumption were surveyed in the area of sago origin and the other areas subsequently adopted sago palm in Indonesia. The original starch extraction method was to pulverize the sago pith with an ax and wash the pieces of pith by hand, which was practiced in NGI. Then this technology of starch extraction was transferred to western Indonesia through the process described below.

Pith pulverization: Original form of pith crushing by ax (chopping with an ax while sitting and a long ax while standing) transferred to west part of Indonesia and Malaysia, followed by further development in grater forms and adaptation to rasper machine use.

Washing pieces of crushed pith: Original form of washing by hand was transferred to the west for further modification of crushing the pith by foot with highpressure water (pumping and gravity) form. This form of washing by water flow is a transformation from a horizontal to a vertical direction.

Sago starch is used for various foods from papeda (dough type with soup) as a staple food to confectionery products (lempeng, baked crackers, cookies, or jellies), noodles, and dry powder (a substitute for other starches).

An important aspect of sago production system depends on farmers' needs, whether they sell it or utilize it themselves. The next important issue is to increase production for the commercial market. In this step, group production system is adapted in the process. This group work is performed by farmers which is the target for specialized business. In addition, mechanization has been introduced, like using a rasper for grating and a pump for washing the pith. These transformations indicate how to develop an efficient economic output. Sago is changing from the concept of staple food to other starch food uses and starch goods use, as the social economy and cash-based economy are developed in the rural Indonesian society.
\end{abstract}

\footnotetext{
Y. Nishimura $(\square)$

Formerly, Nagoya University, Nagoya, Japan

e-mail: nishimuratomobe@gmail.com
} 


\subsection{Introduction}

The sago palm, which originated in New Guinea Island, has created the sago culture that is the means of livelihood for local people where the palm occurs. The traditional dietary food culture of sago has developed under the conditions of different traditions of consumption and extraction of the starch. It is considered that the socioeconomic conditions determine the regional forms of sago extraction and use. Thus the changes in extraction technology have modified the forms of using sago. This subject was investigated in Indonesia where sago palm grows widely, extending from east to west. The factors relating to the various forms are also considered in this chapter.

The prototype of the starch extraction method is found in New Guinea and uses a hand ax type of pulverization of the palm pith and the hand-washing method for extraction of starch from crushed pith. Furthermore, the pulverization method was transformed through the following process modifications: hand ax or hatchet (sitting type), broadax (standing type), grater type (rasping model), and rasper (mechanization pulverization). Moreover, the starch extraction method, which washes pulverized pith, was also transformed as follows: the hand-washing type, the footwashing type, and the pump-use type (providing high pressure) (Nishimura 2015).

As for utilization, sago starch shifted from ugari as the staple food to various food uses. It is supposed that development from a staple food moved with the flow of confectionery (baked crackers, cookies) to noodles and to flour (substitution of other starch flour) (Hirao 2015). At present, sago starch as well as other starches can produce sugar and the materials for plastics through changing the starch character. The nature of these changes is related to the socioeconomics of production and consumption areas.

This paper clarifies the following points in consideration of the two factors of a geographical flow and time flow regarding the extraction method of sago starch. These are the change of method by geographical factors, change of consumption patterns of starch, and, in addition, the relationship between methods of change and the regional economy.

This study is based on results obtained from sago palm investigations in Indonesia conducted from 1992 to 2014. Moreover, some results of investigation from Mindanao, the Philippines, and Papua New Guinea are also included. The study concludes by incorporating results of the investigations in the field and interviews with people in the study areas.

\subsection{Changes in Sago Starch Extraction}

The extraction technique of sago starch is an important task for sago-producing farmers; there are traditional extraction methods and technologies in each local area. It is recognized that there are regional differences even if the technology appears to be simple (Nishimura and Laufa 2002). This study examines the 
technologies or methods of sago starch extraction in Indonesia, a country extending for over $5000 \mathrm{~km}$ from east to west. As a result, the investigation found that there was a difference of the methods in New Guinea, which was the place of origin of a sago palm, and the western regions of Indonesia, to which sago spread. The difference of these methods has taken the form of technology transfer from the original area and a series of improvements in technology in each area.

The study analyzed in detail elements of the technology of four types: the New Guinea type, the Malay type, the intermediate type, and the mixed type as classified by Nishimura (2008b, 2012). From this analysis, enhanced investigations have been carried out, with the results shown in Table 16.1.

In New Guinea, a prototype of the extraction method (New Guinea type) was developed, and there are two forms for the pulverization of sago pith, sitting and standing. The tools used for this work of chopping are a sitting form using a hand ax (chopping ax/hatchet) and a standing form using a common ax (broadax). With the Malay type, which is a more developed type, the sitting form uses a hand ax as a basic form, and a grater form has also been developed. Moreover, the mechanization using raspers is progressing. The intermediate type is a sitting form using a hand ax. Moreover, in Mindanao, Philippines, there is a standing form involving a broadax considered as a mixed type (Nishimura 2008a).

The method of washing the mashed sago pith and extraction of starch exhibits regional differences like pulverization. The New Guinea type is a method in which water is poured in from the side by hand. More elaborate equipment may be made in some cases. In this case, the water flow is from the side (horizontal). Moreover, the Malay type is a starch extracting process which places the mashed pith into a basket where it is washed by foot action under pouring water. The water flow is vertical in this case. The intermediate type is the same as the Malay type which places the mashed pith into a basket and washing it by foot action under a vertical water flow. On the other hand, the method in Mindanao, Philippines, is the technology called the mixed type, and the flow of water is vertical although the mashed pith is washed by hand. Moreover, the mixed type which washes mashed pith by hand by

Table 16.1 Grouping of the regional methods of sago starch extraction

\begin{tabular}{l|l|l|l|l}
\hline \multirow{2}{*}{ Extraction form } & \multicolumn{2}{|l|}{ Sago palm with chopping } & \multicolumn{2}{l}{ Starch extraction by water } \\
\cline { 2 - 5 } & Pulverization & Chopping tools & Washing by & Water flow \\
\hline Original form (New Guinea type) & Sitting & Hatchet & Hand & Horizontal flow \\
\cline { 2 - 3 } & Standing & Broadax & & Horizontal flow \\
\hline Intermediate form (K) & Sitting & Hatchet & Feet & Vertical flow \\
\hline Intermediate form (B) & & & Hand & Vertical flow \\
\hline Developed form (Malay type) & Standing & Grater & Feet & Vertical flow \\
\cline { 2 - 5 } & Standing & Rasper & Feet & Vertical flow \\
\hline Mixed form & Standing & Broadax & Hand & Vertical flow \\
\hline
\end{tabular}

Note:

Type/form: New Guinea T.; Intermediate F.; Malay T.; Mixed F.

Observed region: South Sorong; (K) Kendari, (B) Bogor; Riau; Mindanao 
vertical water flow is seen as a peculiarity in Bogor, Java Island. In the case of comparison of these methods, origin/prototype and developed type, the pith pulverization went from a hand ax to a broadax and then a grater. Moreover, the method of starch extraction by washing in water has evolved from horizontal washing by hand (rubbing) to vertical washing by foot (crushing). Then, a mechanical motorized rasper came into use.

The local processing of sago palm is demonstrated using photographs (Fig. 16.1): the technical change of the pith-crushing work and washing (starch extraction) of the crushed pith, as currently performed in each area. In the case of diffusion of sago technology spreading from Papua Province, Indonesia, and New Guinea Island, the place of origin of sago palm, to the west, technology of the pulverization was transmitted from the east to the west changing to hand ax (sitting form), broadax (standing form), grater form (rasping model), and rasper (mechanization pulverization). Moreover, the method of washing crushed pith by water (starch extraction) changes, moving east to west similarly, going from hand to foot, and finally to the pump-use form. With the addition of a time factor, mechanization becomes technical development.

\subsection{Changes in the Form of Starch Utilization}

Sago palm is an important crop, and the entire plant can be used by native Indonesians. The starch which is extracted serves as the staple food of people in the villages. It is clear that the areas of Indonesia which are located closer to New Guinea Island have a stronger dependence on sago as their staple food. In Kendari, Southeast Sulawesi, and South Sorong, West Papua province, a comparison was made between the staple food and other food. The results are shown in Table 16.2.

In the West Papua province, South Sorong district, and Metamani subdistrict, the staple food is sago, and it is eaten as papeda (porridge). There is also in their diet fish, shellfish, and wild animal meat, such as wild boar, deer, etc., obtained by hunting, as side dishes. On the other hand, in the Kendari district in Southeast Sulawesi, the staple food is rice and sago. Although rice as the staple food was grown as upland rice a long time ago, paddy rice is now cultivated. When indigenous people harvest rice, they eat it in the dry season; during the rainy season, they extract starch from the sago palm. Thus these two plants together provide their staple food. Side dishes in the diet are fish, shellfish, and wild animal meat, similar to West Papua. Cultivation of rice in Indonesia did not take place in the eastern part bordering Sulawesi (Takaya 1990). However, it can be seen that the movement of rice consumption as a staple food spread from the western to eastern regions where the main food is sago. Therefore, traditionally people in the eastern region most commonly consume sago starch as the staple food. Moreover, a unique use of sago starch is processed as noodles. Production of these noodles is mainly carried out in Semarang, Central Java. Since many Chinese immigrants have lived in Java since ancient times, production of the noodles as Chinese food was accomplished. However, sago starch is not produced in Semarang, and the sago starch used to make noodles is mainly brought from the Riau Province (commercialization). Moreover, confections are made as 
16 Sago Starch: Transformation of Extraction and Consumption Processes...

1. Pulverizing pith with sitting form

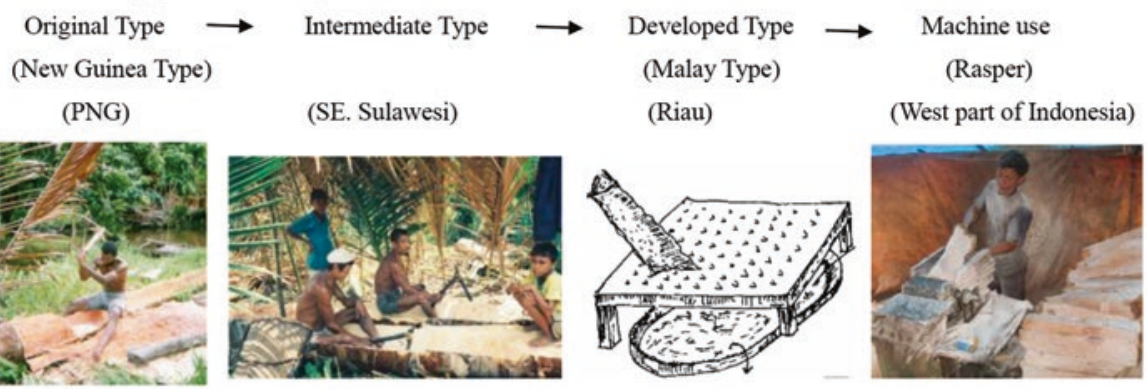

2. Pulverizing pith with standing form
Original Type
$\rightarrow$ Mixed Type
$\rightarrow \quad$ Developed Type
$\rightarrow \quad$ Machine use
(New Guinea Type)
(S. Sorong)
(Mindanao)
(Malay Type)
(Rasper)
(Riau)
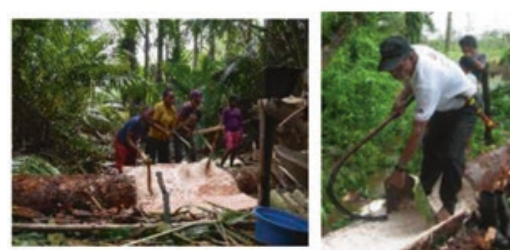

3. Starch extraction by washing (hand-rubbing from and horizontal water flow)

Original Type $\longrightarrow$ Original Type $\rightarrow$ Original Type (improved) $\rightarrow$

Machine use

(New Guinea Type)

(PNG)

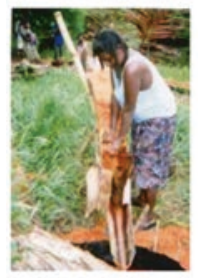

(S. Sorong)

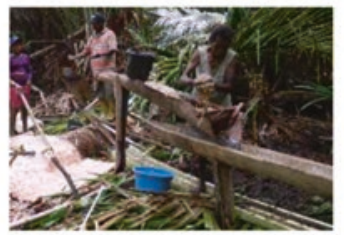

(Sub. Sorong city)

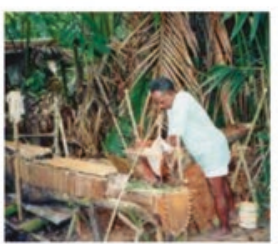

(Pump)

(Bogor)

\section{Starch extraction by washing (foot-paddling form and vertical water flow)}

Developed Type (Malay Type) $\longrightarrow$ Machine Use (pump)

(SE. Sulawesi)

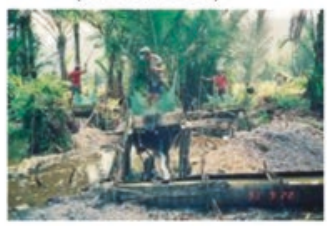

(SE. Sulawesi)

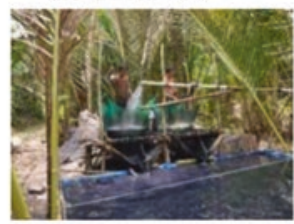

5. Mixed Type

(hand-rubbing form but vertical water flow)

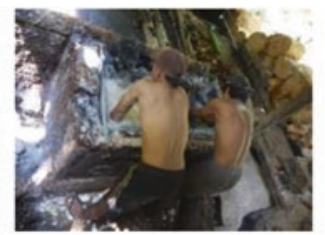

Fig. 16.1 The diffusion and transformation of the methods of sago starch extraction 
Table 16.2 Food situation in sago villages

\begin{tabular}{l|l|l|l|l}
\hline \multirow{2}{*}{ Main food } & \multicolumn{2}{|l|}{ Kiaea village $^{\mathrm{a}}$} & \multicolumn{2}{l}{ Saga village $^{\mathrm{b}}$} \\
& Rice & $99.4 \%$ & Sago & $100 \%$ \\
\cline { 2 - 5 } & Sago & $52.6 \%$ & Rice & A little \\
\cline { 2 - 5 } & Corn & $42.1 \%$ & Banana & Sometimes \\
\cline { 2 - 5 } & Cassava & $2.9 \%$ & & \\
\hline \multirow{5}{*}{ Side dish } & Fish & & Fish & \\
\cline { 2 - 5 } & Shrimp & & Shrimp, Shellfish & \\
\cline { 2 - 5 } & Meat & & Wild animal meat & \\
\cline { 2 - 5 } & Vegetable & & Vegetable & \\
\hline
\end{tabular}

${ }^{a}$ Kiaea village in Southeast Sulawesi province; observation was done in 1992 (Nishimura 1995)

${ }^{b}$ Saga village in West Papua province, located in a wild sago forest. Observation was done in 2012

additional food. One form is lempeng (pancake), which is generally dried food, and can also be considered a preserved food. As well, cookies, shrimp crackers, sago pearls, etc. are made (Hirao 2015). Although confections are made and eaten by the farmers themselves, in many cases they are sold. Moreover, there are some people who make confections, especially in the towns. These forms change depending on regions, and in order to carry out sales, producers need to prepare a product suitable to meet the needs of local consumers.

According to the results of this study, the form of consumption of sago starch is classified into staple food, confections, starch flour, and biomaterial. Traditional farmers in sago palm areas consume sago starch as the staple food and as a confection. Depending on the developing rural economy, the use of sago is diversified and increasingly used as a confection and commercial starch. If the multiple use of this staple food progresses, it will shift from the use of sago starch to uses other than as a staple food. Looking at the usage of the sago starch regionally, diversification of the staple food is moving from east to west. That is, there is one staple food of sago in the provinces of Papua and Maluku to the east, but moving west to Sulawesi and the central islands, there are two staple food areas of rice and sago starch. Also, sago starch goes more to the development of confections and a commercial use to make noodles, such as in Java. Furthermore, in the Malay region on the western side of Kalimantan Province, it has shifted more to commercial starch use. This trend shows a change from east to west, similar to the change in sago starch extraction techniques. Therefore, the form of consumption of sago starch relates to the level of economic development of an area and to social change.

As for sago starch as a staple food, it is eaten in two forms, added to dishes such as soup or porridge, or as a dry food as a bread or biscuit. It is also consumed in the form of noodles made of sago starch. In confectionary form it is consumed as a specialty in Indonesia as crackers, cookies, or jelly. In traditional villages, the confectionery form is generally dry and consumed as a cracker. In addition, in a village on Mindanao Island, Philippines, the confectionery is made of sago starch fried in oil or steamed (Nishimura 2008a). Therefore, sago starch is important as a staple food in eastern Indonesia and consumed as a side dish or confectionery in the western part of the country. It is believed that this tendency is especially influenced by 
the Java culture which eats sweets (diversification of a meal). Furthermore, in the western Malay area, as commercialization progresses toward industrial uses such as starch flour, food use in the rural area of sago starch is being reduced.

\subsection{Technical Flow and Economic Positioning}

It is believed that sago starch extraction technology spread to the western region of Indonesia from New Guinea, the place of sago origin. Extraction technology has improved into an appropriate form in each place over the process of this diffusion. The improved technological conditions are based on the development situation of sago villages. The production systems of sago starch differ in villages where sago is only a staple subsistence food and villages where sago is produced for sale. The rural socioeconomic situation becomes one of the factors for different forms of the production system. The economy of Java is the most developed in Indonesia. However, the economy is still underdeveloped elsewhere, especially in the eastern Indonesia islands. The economy and the social conditions of the study areas are shown in Table 16.3. Therefore, the socioeconomic conditions are still low for the areas of the eastern island region near the origin center of sago.

It is possible to consider how the starch extraction method currently found in each region has been changed from the prototype of New Guinea. The changing technology in an area, considering the form of the process from east to west, is shown in Table 16.4.

For the change of extraction technology, it is clear that the pulverization method of New Guinea of using an ax became a grater-type technology in and to the west of Sulawesi. In this development process, the use of mechanical raspers began. Similarly, also in the extraction technology, it changes from the hand-rubbing method which is the prototype to the more efficient foot-mashing method on Sulawesi Island in the western region. Also, pumping water under high pressure was introduced to this method, giving an improved and more efficient technology. However, the method of hand rubbing in Bogor is carried out by flushing water by gravity. This situation indicates that technology has developed toward the west from the east. This phenomenon is related to the social development situation of sago societies; economic conditions, especially, are a key factor in the development. That

Table 16.3 GDP and literacy rate in main islands in Indonesia

\begin{tabular}{l|l|l}
\hline Area (islands) & $\begin{array}{l}\text { GDP('000Rp)/ } \\
\text { capita }\end{array}$ & Literacy rate (\%) \\
\hline Sumatra & 2447 & 92.8 \\
\hline Java & 2275 & 86.5 \\
\hline Kalimantan & 3774 & 89.2 \\
\hline Sulawesi & 1289 & 86.8 \\
\hline Others & 1377 & 77.9 \\
\hline
\end{tabular}

Source: Statistic Indonesia (BPS), Financial Statistics (BPS) by OECF (1998) 
Table 16.4 Flow of the methods of sago starch extraction in Indonesia

\begin{tabular}{|c|c|c|c|c|}
\hline \multirow{2}{*}{ Developed steps } & \multirow{2}{*}{ Relevant island } & \multirow{2}{*}{$\begin{array}{c}\text { spread } \\
\text { flow }\end{array}$} & \multicolumn{2}{|c|}{ Technology and tools } \\
\hline & & & Palm pith pulverization tools & Sago extraction with wash by rubbing \\
\hline Original Type & New Guinea & east & hatchet type $\leftrightarrow$ broadax type & by hands (horizontal water flow) \\
\hline$\downarrow$ & & region & & \\
\hline Intermediate Type & Sulawesi & 1 & hatchet type & by feet (vertical water flow) \\
\hline \multicolumn{5}{|l|}{$\checkmark$} \\
\hline Developed Type & Sumatra, Sulawesi & & grater & by feet (vertical water flow) \\
\hline$\downarrow$ & & $\downarrow$ & & \\
\hline \multirow[t]{4}{*}{ Machine Use Type } & Sumatra & west & rasper & by feet with pumped up water \\
\hline & Java & region & & (vertical water flow) \\
\hline & & & & by hands with gravity pressure water \\
\hline & & & & (holizontal water flow) \\
\hline
\end{tabular}

is, the sago starch which is used only as a staple food is diversified for use in confectionery. The factor influencing the change in sago utilization is related to the background of the needs of consumers and markets. It is apparent that the greater diffusion of sago palms going toward the western regions, where there is a strong economy, the more diversification of sago utilization and extraction technology takes place. Therefore, the transformation in extraction and consumption process of sago starch depends on the development situation of the society and the economy in the regions.

\subsection{Conclusion}

Sago starch extraction methods, pith pulverization and washing mashed pith by rubbing, changed their forms and diffused from place to place, spreading from the eastern regions. The changing factor of the method relates to the social economy and trade situation of the areas. The changes influence improvements toward practices that are more efficient and economical. In an area where the social economy and cashbased economy are developed, sago utilization shifts from staple food use to starch goods use. Commercialization of sago is determined by the result of comparison with the price of rice for staple food and other starch use for confectionery products.

Therefore, sago starch changes into a side dish of confectionery from a staple food, in areas of more developed economies. And sago has become the alternative (complementary) staple food of rice. Societies where sago became the staple food in the area do not have a developed economy, but sago becomes the alternative staple food in those more developed areas which have rice. It has already progressed as a food material for confectionery in the area in which it is no longer the staple food. Moreover, noodles are produced as a unique form of consumption and are considered to have been influenced by Chinese food culture. And it has changed in terms of the consumption needs from a subsistence food to a market product. The utilization and production forms of sago can be seen under the following circumstances:

1. Staple food for subsistence - family work (New Guinea)

2. Supplement of the staple food - family/specialization work (Sulawesi) 
3. As a commercial product-formation of special production groups (east of Sulawesi)

4. Commercialization/industrialization (Sumatra, Sarawak, Malay Peninsula)

The development circumstances of sago palm use in Indonesia have progressed from east to west. In order to shift development into commercialization from the stage of subsistence use of sago starch, the degree of socioeconomic development, consumption needs, and transportation development are indispensable factors. Moreover, it is simultaneously necessary to consider the time factor of the development standard of each area. Therefore, time flow (for the axis of regional development) becomes an important factor as well as regional factors for studying a technical change of the diffusion of the method. Therefore, it is necessary to take into consideration not only the changes in technology but also the time factor (development axis of the region) as well as the socioeconomic condition of a region for the full development of sago starch production.

\section{References}

Hirao K (2015) Use as food, starch properties and use. The sago palm. The Society of Sago Palm Studies, Kyoto Univ Press, pp 264-272

Nishimura Y (1995) Agriculture in the villages of Southeast Sulawesi, Indonesia - part 1. the intervillage variations in food production and consumption. Sago Palm 3:55-61

Nishimura Y (2008a) Present sago palm situation in Mindanao, Philippines. In: Proceedings of the 17th conference of the society of sago palm studies. Mie, Japan, pp 31-36 (in Japanese)

Nishimura Y (2008b) Different methods of sago starch extraction depending on different areas, Trop Agr Develop Sym Presentation

Nishimura Y (2012) Changing and diversification of sago palm utilization. In: Food and farming being nurtured by biodiversity. Commons Co. Ltd., Tokyo. pp 133-148 (in Japanese)

Nishimura Y (2015) Traditional extraction methods, starch extraction and production. In: The sago palm. The Society of Sago Palm studies, Kyoto Univ Press, pp 235-242

Nishimura Y, Laufa TM (2002) A comparative study on technology adaption for sago starch extraction in Pacific and Asian local regions. Sago Palm 10(1):7-17

OECF (1998) Present situation and problems of regional gap in Indonesia. OECF research paper no. 23 (in Japanese)

Takaya Y (1990) How is rice considered? NHK Books, p 226 (in Japanese)

Open Access This chapter is licensed under the terms of the Creative Commons Attribution 4.0 International License (http://creativecommons.org/licenses/by/4.0/), which permits use, sharing, adaptation, distribution and reproduction in any medium or format, as long as you give appropriate credit to the original author(s) and the source, provide a link to the Creative Commons license and indicate if changes were made.

The images or other third party material in this chapter are included in the chapter's Creative Commons license, unless indicated otherwise in a credit line to the material. If material is not included in the chapter's Creative Commons license and your intended use is not permitted by statutory regulation or exceeds the permitted use, you will need to obtain permission directly from the copyright holder. 